\title{
Integration of Optically Generated Impulse Radio UWB Signals into Baseband WDM-
} PON

Pham, Tien Thang; Yu, Xianbin; Dittmann, Lars; Tafur Monroy, Idelfonso

Published in:

I E E E Photonics Technology Letters

Link to article, DOI:

10.1109/LPT.2011.2109943

Publication date:

2011

Link back to DTU Orbit

Citation (APA):

Pham, T. T., Yu, X., Dittmann, L., \& Tafur Monroy, I. (2011). Integration of Optically Generated Impulse Radio UWB Signals into Baseband WDM-PON. I E E E Photonics Technology Letters, 23(99).

https://doi.org/10.1109/LPT.2011.2109943

\section{General rights}

Copyright and moral rights for the publications made accessible in the public portal are retained by the authors and/or other copyright owners and it is a condition of accessing publications that users recognise and abide by the legal requirements associated with these rights.

- Users may download and print one copy of any publication from the public portal for the purpose of private study or research.

- You may not further distribute the material or use it for any profit-making activity or commercial gain

- You may freely distribute the URL identifying the publication in the public portal

If you believe that this document breaches copyright please contact us providing details, and we will remove access to the work immediately and investigate your claim 


\title{
Integration of Optically Generated Impulse Radio UWB Signals into Baseband WDM-PON
}

\author{
Tien-Thang Pham, member, IEEE, Xianbin Yu, member, IEEE, Lars Dittmann, member, IEEE and \\ Idelfonso Tafur Monroy, member, IEEE
}

\begin{abstract}
We propose a compact integration system to simultaneously provide wireline and wireless (baseband and ultra-wide band (UWB)) services to end-users in a WDM-PON. A 1-Gbps UWB signal is optically generated and shares the same wavelength with the baseband signal. Error-free performance was achieved after $23-\mathrm{km}$ single mode fiber (SMF) transmission for both signals and additional $0.4-\mathrm{m}$ wireless transmission for the UWB signal. The low complexity and high spectrum efficiency of this system makes it attractive for deployment of in wireline/wireless converged gigabit optical access networks.
\end{abstract}

Index Terms - Microwave photonics, passive optical network (PON), radio over fiber (RoF), ultra-wideband (UWB), wavelength division multiplexing (WDM).

\section{INTRODUCTION}

$\mathrm{R}$ ECENTLY, there is a increasing demand from service providers to simultaneously support multiple wireline/ wireless broadband services to end-users in a converged optical access network. A wavelength division multiplexedpassive optical network (WDM-PON) is considered as the backbone of a converged network for provision of both wireline and wireless services because it offers several advantages such as large bandwidth, long reach, high power budget, excellent security and easy upgradeability $[1,2]$.

Ultra-wide band (UWB) is a promising technology for short range wireless communication systems due to its low complexity, low cost, low power consumption and coexistence with other radio communication systems. Regulated by the Federal Communications Commission (FCC), UWB operating within the spectrum band $3.1-10.6 \mathrm{GHz}$ has extremely low emission power at $-41.3 \mathrm{dBm} / \mathrm{MHz}$ [3]. As a result, achievable wireless transmission distance is limited in a few meters. To extend the reach of UWB services, UWB-over-fiber technologies with different schemes have been proposed recently [4-8]. Additionally, some works have demonstrated the possibility to increase the spectrum efficiency of WDM-PON networks and optical in-home networks by simultaneously transmitting baseband and the electrically generated UWB signals $[9,10]$. The baseband signal is combined with the UWB signal using electrical combiner and then modulates an optical source. To further exploit the

Manuscript received Sep 27, 2010; revised Dec 23, 2010; accepted Jan 22, 2010.

The authors are with DTU Fotonik, Department of Photonics Engineering, Technical University of Denmark, 2800 Kgs. Lyngby, Denmark (e-mail: ptit@fotonik.dtu.dk).

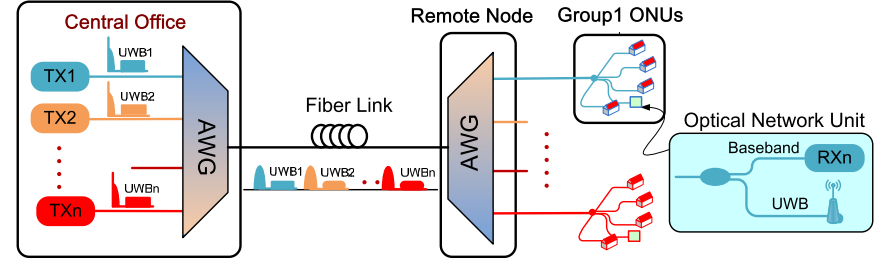

Fig. 1. Schematic of proposed WDM-PON system for simultaneous provision of wireline and UWB wireless services. TXn: $n$th channel transmitter, RXn: $n$th channel receiver, AWG: array waveguide grating.

advantages of photonic technologies such as high-speed generation and no requirement of combining electrical signals, it is desirable to directly generate and integrate the UWB signal in the optical domain.

In this letter, we propose and experimentally demonstrate a WDM-PON system that simultaneously provides gigabit baseband service and gigabit impulse UWB (IR-UWB) service on a single wavelength. The UWB signal is optically generated based on relaxation oscillations of a directly modulated laser (DML). Both signals were transmitted over $23 \mathrm{~km}$ of single mode fiber (SMF). The detected UWB signal was further transmitted over 0.4-m wireless link. Offline digital signal processing (DSP) receivers were employed to demodulate the signals and assess their bit-error-rate (BER) performance.

\section{NETWORK ARCHITECTURE AND EXPERIMENTAL SYSTEM}

Fig. 1 depicts the downlink topology of a WDM access network supporting wireline and UWB wireless services. A central office (CO) is composed of a laser array with $n$ transmitters (TXs) which offer WDM wavelengths for downlink. Two arrayed waveguide gratings (AWGs) operate as a wavelength multiplexer and a demultiplexer, respectively. At the optical network unit (ONU) side, after a single mode fiber (SMF) link, a downstream receiver is used to demodulate the baseband signal, and a transmitting antenna is employed to radiate the UWB signal to the air. In this scenario, a number of ONUs in a cluster can share a single wavelength and broadcast services on this wavelength.

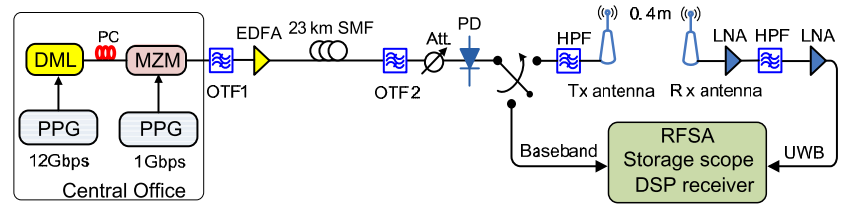

Fig. 2. Experimental setup of the proposed fiber-wireline/wireless transmission system. PPG: pulse pattern generator, DML: directly modulated laser, EDFA: Erbium-doped fiber amplifier, MZM: March-Zender modulator, PD: photodetector, Att: tunable optical attenuator, HPF: high pass filter, LNA: low noise amplifier, RFSA: RF spectrum analyzer. 
Fig. 2 shows the experimental system supporting optically generated IR-UWB and wireline baseband services. At the CO, for a channel, a high-speed baseband signal drived a directly modulated laser (DML) to generate a UWB signal based on relaxation oscillations [5]. The lightwave from the laser was launched into a March-Zender modulator (MZM) which was driven by the second baseband signal. Two optical tunable filters (OTFs) were used to emulate AWGs. The optical carrier was located at the right side slope of the OTF1 to modify the pulse shape of the UWB signal to better comply with the FCC mask [4]. The low frequency RF components can be greatly suppressed for the integration of baseband signals. The OTF2 simply suppressed amplified spontaneous emission (ASE) noise from erbium-doped fiber amplifier (EDFA). At the ONU, both the UWB and baseband data were recovered by a single photodetector (PD) and separated by proper filters. The UWB signal was then radiated into the air through a transmitting antenna.

Both the baseband and UWB data were demodulated offline employing a DSP receiver composed of a $40-\mathrm{GSa} / \mathrm{s}$ digital storage oscilloscope (DSO) and offline DSP algorithms. For the baseband data, the unfiltered detected signal from the PD was recorded. For the UWB data, the signal from the receiving antenna was amplified, filtered and then stored by the DSO.

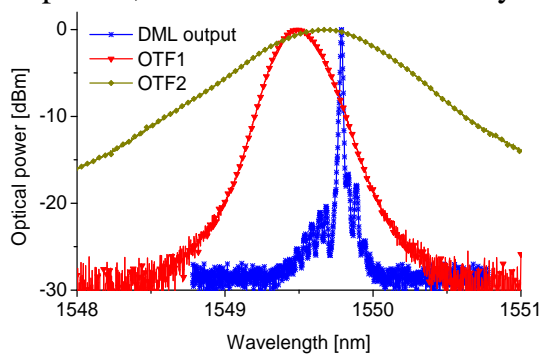

Fig. 3. Normalized optical spectrum of DML output and bandwidth profiles of two optical tunable filters (OTFs).

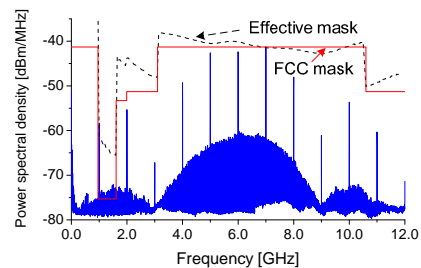

(a)

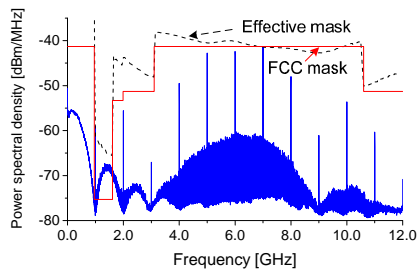

(b)
Fig. 4. Detected electrical spectra at $-12.5 \mathrm{dBm}$ optical power a) without baseband signal and $\mathrm{b}$ ) with baseband signal.

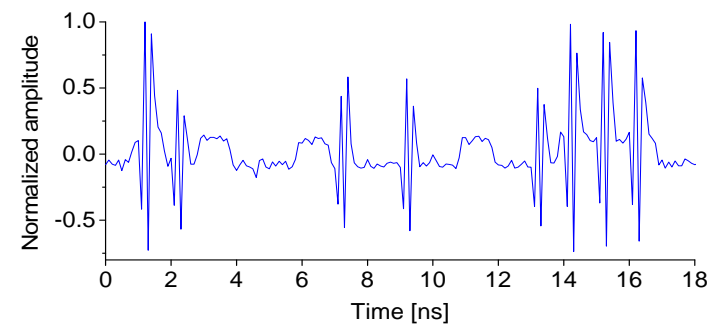

Fig. 5. The hybrid (baseband and IR-UWB) waveform of the detected signal.

\section{EXPERIMENTAL RESULTS}

In the experiment, lasing threshold current and bias current of the DML - $21 \mathrm{~mA}$ and $-34 \mathrm{~mA}$, respectively. The DML was driven by a pulse pattern generator (PPG) at 12-Gbps and 0.625-V peak-to-peak voltage $\left(\mathrm{V}_{\mathrm{p}-\mathrm{p}}\right)$ with a pattern "1010 0000
0000" to present UWB bit " 1 " and a pattern "0000 00000000 " to present UWB bit " 0 ". The effective bit rate for the generated UWB signal was thus 1 Gbps. The output optical carrier is then externally modulated by a 1-Gbps baseband PRBS with a word length of $2^{15}-1$ from the second PPG at the MZM. 3-dB bandwidth of two OTFs was $0.308 \mathrm{~nm}$ and $0.948 \mathrm{~nm}$, respectively. The offset between the transmission wavelength and the central wavelength of OTF1 was $0.3 \mathrm{~nm}$. The optical spectrum of the DML output and the bandwidth profiles of two OTFs are shown in Fig. 3. The bandwidth of the PD was 12-GHz. The UWB signal was radiated into the free space by an Omni-directional antenna (Skycross SMT-3TO10M-A). The wireless transmission distance was set at $0.4 \mathrm{~m}$ for demonstration purpose. The radiated UWB signal was received by a directive antenna (Geozondas AU-3.1G10.6G-1) pointed towards the transmitting antenna.

No electrical amplifier was used after the PD. In this condition, to ensure UWB spectrum was FCC-compliant, the maximum optical power launched to the PD was $-12.5-\mathrm{dBm}$. Fig. 4 shows the electrical spectra after fiber transmission at this power. The effective mask is the allowed mask when the frequency response of the transmitting antenna was taken into account [8]. The baseband signal did not alter the spectrum of the UWB signal in the main frequency region $(3-9 \mathrm{GHz})$. The detected hybrid waveform is shown in Fig. 5. There were two levels for the pulse amplitude of UWB bits " 1 " when they co-existed with baseband bits. Baseband bits " 1 " increased the pulse amplitude of UWB bits " 1 " when they overlapped in time domain. It is because the baseband signal modulated the intensity of the optical carrier after the UWB signal.

\section{A. Performance of the UWB data}

The DSP demodulation algorithm for the UWB signal comprised four steps: high-pass filtering, bit correlation, bit synchronization and threshold gating [6]. Fig. 6 illustrates the transmission performance of 50,000 generated UWB bits after $0.4-\mathrm{m}$ wireless transmission, with and without the co-propagation of $0.5-\mathrm{V}$ baseband data. There were no errors detected in all cases when the optical power was higher than $-14 \mathrm{dBm}$. We can notice that $23-\mathrm{km}$ fiber transmission introduced about 2-dB power penalty which is mainly caused by fiber chromatic dispersion. It was because relaxation oscillations of direct modulation broadened the spectrum of the optical signal from the DML and the UWB signal occupied a broad bandwidth. Moreover, the co-propagation of baseband signal caused approximately 1-dB power penalty.

As two signals share the same optical carrier, there is a trade-off between their performances [2]. To further assess the effect of the baseband signal on the performance of the UWB signal, we varied the $\mathrm{V}_{\mathrm{p}-\mathrm{p}}$ of the baseband data while the optical power at the receiver was fixed at $-12.5 \mathrm{dBm}$. No error was detected in 50,000 bits when the $\mathrm{V}_{\mathrm{p} \text {-p }}$ was below $0.625 \mathrm{~V}$ as presented in Fig. 7. When the $\mathrm{V}_{\mathrm{p}-\mathrm{p}}$ increased from $0.75 \mathrm{~V}$ to $1.0 \mathrm{~V}$, BER of the UWB signal increased from $1.26 \times 10^{-4}$ to $2.51 \times 10^{-3}$. At this optical power level, for the baseband data, BER $<10^{-9}$ could be achieved at $0.250-\mathrm{V} \mathrm{V}_{\mathrm{p}-\mathrm{p}}$ as presented in next section. The inset shows the eye-diagram after DSP processing for the case with the baseband data. 


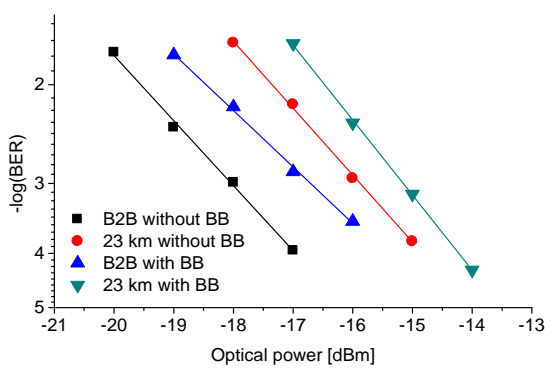

Fig. 6. Measured BER of the UWB signal after 0.4-m wireless transmission.

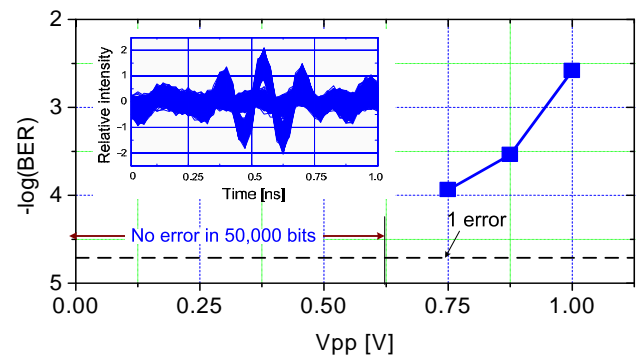

Fig. 7. BER of the UWB signal at different $\mathrm{V}_{\mathrm{p}-\mathrm{p}}$ of the baseband signal. Inset: measured eye-diagram with $0.5-\mathrm{V}$ baseband signal.

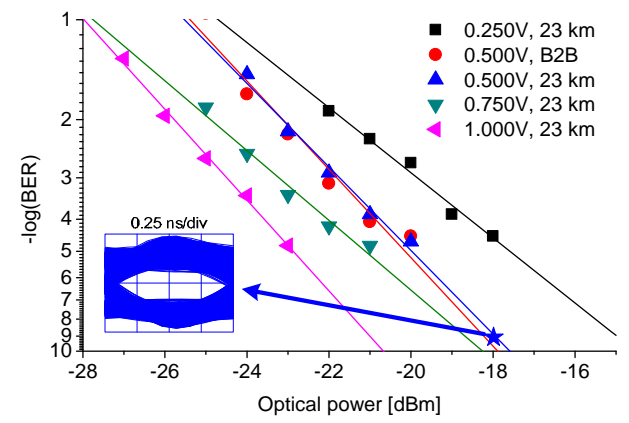

Fig. 8. Measured BER of the baseband signal. Inset: the eye-diagram at $-18 \mathrm{dBm}$ after 23-km transmission.

\section{B. Performance of the baseband data}

The DSP algorithms for baseband signal included low-pass filtering with 900-MHz cut-off frequency, synchronization and threshold decision. This cut-off frequency ensures that the repetition frequency at $1 \mathrm{GHz}$ of the UWB signal is rejected to reduce the interference from the UWB signal. Fig. 8 shows the measured BER curves of 100,000-bit baseband data at different $\mathrm{V}_{\mathrm{p}-\mathrm{p}}$. We can notice that at the same optical power to the PD, BER decreased with the increase of $\mathrm{V}_{\mathrm{p}-\mathrm{p}}$. In a linear transmission system, $\log (-\log (\mathrm{BER}))$ is proportional to the received optical power, therefore by extrapolating the BER curve, error-free transmission $\left(\mathrm{BER}<10^{-9}\right)$ is predicted to be able to achieve at $-21 \mathrm{dBm}$ to $-15 \mathrm{dBm}$ when the $V_{\mathrm{p}-\mathrm{p}}$ was decreased from $1.0 \mathrm{~V}$ to $0.25 \mathrm{~V}$. The power penalty induced by after 23-km fiber transmission is negligible as it can be seen from the $0.5-\mathrm{V}$ modulation case. The inset shows the measured eye-diagram after transmission at $-18-\mathrm{dBm}$ optical power. At this optical power, BER $<10^{-9}$ could be achieved.

The experimental results show the existence of the trade-off between the performance of the baseband and UWB signals. The higher modulation index of the baseband signal, the better the performance of baseband data but the worse the performance of the UWB data. We also can notice that the required optical power for the baseband data to reach the forward error correction (FEC) limit $\left(\mathrm{BER}<2 \times 10^{-3}\right)$ was always lower than that for the UWB service even at the driving voltage of $0.25-\mathrm{V}$. To satisfy performance requirement for both the data at a fixed optical power level, the $\mathrm{V}_{\mathrm{p}-\mathrm{p}}$ of the baseband signal can be further reduced. With such low modulation depth, the optical carrier can be reused for uplink baseband data transmission in reflective semiconductor optical amplifier (RSOA) based WDM-PON systems [1, 2]. On the other hand, to improve the performance of the UWB signal at low optical power, an electrical amplifier with a power control mechanism can be used for the UWB signal. In this condition, the optical power budget for splitting and transmission is increased.

\section{CONCLUSIONS}

A novel scheme for simultaneous provision of optically generated gigabit UWB and baseband services on a single wavelength of a WDM-PON system was proposed and experimentally demonstrated. No error was observed for 1-Gbps baseband data and 1Gbps IR-UWB data after 23-km fiber transmission. The existence of the baseband data caused about 1-dB power penalty on the performance of the UWB data. The integration of the UWB signals into the baseband WDM-PON increases electrical/ optical spectrum efficiency of the whole systems, and thus it has great potential for applications in supporting the development of wireline/wireless convergence in optical access networks.

\section{REFERENCES}

[1] W. Lee, M. Y. Park, S. H. Cho, J. Lee, C. Kim, G. Jeong, B. W. Kim, "Bidirectional WDM-PON based on gain-saturated reflective semiconductor optical amplifiers,” IEEE Photon. Technol. Lett., vol. 17, no. 11, pp. 2460-2462, Nov. 2005.

[2] T. T. Pham, H. S. Kim, Y. Y. Won, S. K. Han, “Colorless WDM-PON based on a Fabry-Pérot laser diode and reflective semiconductor optical amplifiers for simultaneous transmission of bidirectional gigabit baseband signals and broadcasting signal,” Opt. Express, vol. 17, no.19, pp. 16571-16580, 2009.

[3] Revision of Part 15 of the Commission's Rules Regarding Ultra-Wideband Transmission Systems Federal Communications Commission, Feb. 2002.

[4] F. Zeng, J. P. Yao, 'Ultrawideband impulse radio signal generation using a high-speed electrooptic phase modulator and a fiber Bragg grating based frequency discriminator', IEEE Photonics Technol. Lett., 2006, vol. 18, pp. 2062-2064.

[5] X. Yu, T. B. Gibbon, M. Pawlik, S. Blaaberg, I. T. Monroy, "A photonic ultra-wideband pulse generator based on relaxation oscillations of a semiconductor laser,” Opt. Express, vol. 17, no. 12, pp. 9680-9687, 2009.

[6] T. B. Gibbon, X. Yu, I. T. Monroy, "Photonic ultra-wideband 781.25-Mb/s signal generation and transmission incorporating digital signal processing detection,” IEEE Photon. Technol. Lett., vol. 21, no. 15, pp. 1060-1062, 2010.

[7] R. Llorente, T. Alves, M. Morant, M. Beltran, J. Perez, A. Cartaxo, J. Marti, "Ultra-wideband radio signals distribution in FTTH networks," IEEE Photon. Technol. Lett., vol. 20, no. 11, pp. 945-947, Jun. 2008.

[8] M. Abtahi, M. Mirshafiei, J. Magn, S. LaRochelle, L. A. Rusch, "All-optical 500-Mb/s UWB transceiver: an experimental demonstration,” J. Lightw. Technol., vol. 26, no. 15, pp. 2795-2802, Aug. $1,2008$.

[9] S. Pan, J. Yao, "Simultaneous provision of UWB and wired services in a WDM-PON network using a centralized light source,” IEEE Photon. J., vol. 2, no. 5, pp. 711-718, Oct. 2010.

[10] J. B. Jensen, R. Rodes, M. Beltran, I. T. Monroy, "Shared medium 2Gbps Baseband \& $2 \mathrm{Gbps}$ UWB in-building converged optical/wireless network with multimode fiber and wireless transmission,” in Proc. 36th Eur. Conf. Optical Commun.(ECOC) 2010, Italy, Sep. 2010. 